\title{
O PAPEL DO TRABALHO E DA FORMAÇÃO ACADÊMICA NO PROJETO PROFISSIONAL DO TRABALHADOR DA SAÚDE
}

\author{
THE ROLE OF WORK AND EDUCATION ON THE HEALTH WORKER'S PROFESSIONAL PROJECT \\ EL PAPEL DEL TRABAJO Y DE LA FORMACIÓN ACADÉMICA EN EL PROYECTO PROFESIONAL \\ DEL TRABAJADOR DE LA SALUD
}

\author{
Rosimeire Aparecida Manoel ${ }^{1}$ \\ Denise Stefanoni Combinato ${ }^{2}$ \\ Fernanda Márcia de Azevedo Gomes ${ }^{3}$ \\ Katiuska Fabiana da Silva ${ }^{4}$
}

Resumo O objetivo do estudo foi analisar os determinantes para a escolha da Estratégia Saúde da Família como campo de atuação profissional, a fim de verificar a influência da formação acadêmica e suas implicações. Foram entrevistados individualmente, de outubro de 2006 a fevereiro de 2007, 22 profissionais de nível superior (cirurgiões-dentistas, enfermeiros e médicos) de equipes da Saúde da Família de um município de Mato Grosso do Sul. As entrevistas foram gravadas, transcritas e analisadas de acordo com o referencial teórico-metodológico da psicologia sócio-histórica. Observou-se que a escolha profissional para a Estratégia Saúde da Família não ocorreu de forma reflexiva e crítica, sendo influenciada principalmente pela expansão da área e oferta de emprego, o que pode comprometer a atuação profissional. Sugere-se investimento nos processos educativos como uma forma de incentivar e favorecer a atuação e o compromisso dos profissionais com o Sistema Único de Saúde e, especialmente, a Saúde da Família.

Palavras-chave Saúde da Família; psicologia; orientação vocacional.
Abstract This study aimed to analyze the determining factors for the choice of the Family Health Strategy as a field of professional practice in order to check for the influence of academic education and its implications. From October 2006 to February 2007, 22 higher level professionals (dentists, nurses and physicians) working in Family Health teams in a municipality of the state of Mato Grosso do Sul (Brasil) were interviewed individually. The interviews were recorded, transcribed, and analyzed pursuant to the theoretical and methodological framework of socio-historical psychology. It was observed that the professional choice of the Family Health Strategy was not reflective and critical, rather influenced mainly by the expansion of the area and job offers, a fact that may compromise their professional activities. We suggest investing in educational processes as a way to encourage and promote the work and the commitment of professionals with the Health System and, especially, Family Health.

Keywords Family Health; psychology; vocational guidance. 


\section{A Estratégia Saúde da Família como campo de atuação profissional}

A Estratégia Saúde da Família (ESF) foi implantada em 1994 como uma ampliação do Programa de Agentes Comunitários de Saúde (Pacs), que teve início em 1991 no Norte e no Nordeste, com o objetivo de romper com o modelo tradicional de atenção à saúde e priorizar ações de prevenção, promoção e recuperação da saúde de maneira integral e contínua, mediante a participação e proximidade da população (Brasil, 2001a).

O surgimento da ESF foi circundado por um contexto rico de influências, tais como:

A evolução do Sistema Único de Saúde e suas respectivas contradições e incertezas; as experiências pontuais de modelos inovadores da atenção à saúde no Brasil; o perfil epidemiológico brasileiro e a pressão institucional internacional por políticas consistentes de APS [Atenção Primária em Saúde] (Andrade, Bueno e Bezerra, 2008, p. 806).

A proposta é que a unidade de Saúde da Família seja a porta de entrada da população no Sistema de Saúde, possibilitando um aumento no acesso aos serviços de saúde na Atenção Básica. Segundo dados do Departamento de Atenção Básica (DAB) referente ao mês de junho de 2014, a estimativa da população coberta pela ESF é de 115.689 .533 pessoas, representando um percentual de $59,64 \%$ da população brasileira (Brasil, 2014).

A ESF tem representado uma vertente importante no processo de expansão das ações de saúde, o que consequentemente se reflete na ampliação de inserções de profissionais na área. Como apontam Akerman e Feuerwerker (2008), a ESF

tem mobilizado a contratação de um grande contingente de profissionais de saúde no Brasil, com destaque para os médicos e enfermeiras, auxiliares (e técnicos) de enfermagem e agentes comunitários de saúde, presentes em todas as equipes do país (Akerman e Feuerwerker, 2008, p. 181).

Em 2000, a saúde bucal foi inserida na ESF para ampliar o acesso da população às ações e aos serviços de promoção, prevenção e recuperação da saúde bucal (Brasil, 2002a, 2008a). Assim, os profissionais dessa área (cirurgião-dentista, atendente de consultório dentário e técnico de higiene dental) "vêm sendo rapidamente inseridos numa proporção de uma dupla para cada duas equipes de saúde da família" (Akerman e Feuerwerker, 2008, p. 181).

Além dos profissionais que compõem a equipe de referência e a equipe de saúde bucal, outros profissionais começam a se vincular à ESF por meio dos Núcleos de Apoio à Saúde da Família (NASFs), como fisioterapeutas, nutricionistas, psicólogos, educadores físicos, assistentes sociais, entre ou- 
tros, a fim de que atuem na lógica do matriciamento (ou apoio matricial), proporcionando subsídios para a equipe de referência (Brasil, 2008b).

Considerando a significativa expansão da ESF no cenário nacional, em relação tanto à população atendida como à ampliação de suas ações e contratação de diferentes profissionais, questionamos os determinantes para a escolha dessa área de atuação pelos profissionais da saúde e a influência da formação na escolha específica para atuação na Saúde da Família.

De acordo com a perspectiva sócio-histórica, referencial teórico-metodológico adotado neste trabalho, a construção do projeto profissional não resulta de um amadurecimento psíquico e biológico, mas de um processo multideterminado, em que o indivíduo sofre influência de fatores políticos, econômicos, sociais, educacionais, familiares e psicológicos. Portanto, ainda que o projeto profissional seja individual, é preciso ter consciência de que ele recebe várias influências (Bock, 2002; Soares, 2002) e tem consequências sociais, já que o trabalho sempre interfere, de algum modo, no outro ou na sociedade (Luna, 2003). Assim, a elaboração do projeto profissional deve contemplar uma reflexão sobre a maneira como se pretende intervir na rea-lidade, uma vez que o trabalho transforma, ao mesmo tempo, a si mesmo e a sociedade.

Ao adotar a relação homem-trabalho como objeto de estudo, a orientação profissional baseada na abordagem sócio-histórica tem o objetivo de mediar o processo de construção da identidade profissional por meio de reflexões e do conhecimento de si e da realidade. Tal abordagem leva em consideração os aspectos econômicos, sociais e políticos que fazem parte do contexto do trabalho contemporâneo, propiciando a elaboração de projetos profissionais de maneira mais crítica e consciente.

Com base nessa perspectiva, o objetivo desta pesquisa foi analisar os determinantes para a escolha da ESF como campo de atuação profissional, a fim de verificar a influência da formação acadêmica e as implicações para a atuação profissional.

\section{Caminhos percorridos: da aparência para a essência}

Participaram desta pesquisa 22 profissionais de nível superior da equipe da Saúde da Família, a saber: sete cirurgiões-dentistas, dez enfermeiros e cinco médicos que, neste artigo, serão identificados pelas letras D, E e M, ${ }^{5}$ respectivamente, seguidos de números atribuídos aleatoriamente.

Foi selecionado um município do interior de Mato Grosso do Sul em razão de o tempo de existência da Saúde da Família ser relativamente grande (mais de seis anos, no início da pesquisa, em 2006) e ter praticamente $100 \%$ de cobertura. O critério de inclusão delimitado para profissional de nível superior foi adotado porque um dos objetivos desta pesquisa foi analisar a influência 
da formação acadêmica para o estabelecimento do projeto profissional, ou seja, a escolha da ESF como campo de atuação profissional. Com base nesse critério de inclusão, foram feitas tentativas para convidar todos os cirurgiões-dentistas, enfermeiros e médicos da ESF desse município (totalizando 33 profissionais) para participarem da pesquisa. Nem todos foram encontrados no período estabelecido para coleta, e alguns preferiram não participar.

O método de coleta de dados foi a entrevista individual, realizada por meio de roteiro semiestruturado. A entrevista foi realizada no local de trabalho dos profissionais, após leitura e assinatura do termo de consentimento livre e esclarecido. Os principais temas da entrevista foram: a escolha da profissão, a formação nos cursos de graduação sobre a atuação em Saúde Pública, a escolha para inserção na ESF, as atividades desenvolvidas na ESF.

Após a transcrição das entrevistas, realizou-se análise dos dados com base no referencial teórico-metodológico da psicologia sócio-histórica. Buscou-se atender aos princípios explicitados por Vigotski6 (1987):

A análise do processo, e não da coisa; a análise que descobre a ligação e relação dinâmico-causal real, e não a análise que decompõe os traços externos do processo, portanto uma análise explicativa e não descritiva e, por fim, a análise genética, que regressa ao ponto de partida e reestabelece todos os processos de desenvolvimento de uma determinada forma, que, em seu aspecto presente, já aparece como uma fossilização psicológica (Vuigotskij, 1987, tradução nossa, p. 113).7

Por se tratar de uma pesquisa qualitativa, a qual visa, de acordo com Vigotski, a uma análise do processo, explicativa e genética, utilizou-se o discurso como recurso para a análise. Esta análise permite, com base no relato do sujeito, construir um conhecimento que desvele a realidade, isto porque, apesar de o indivíduo ser único, ele contém a totalidade social e a expressa nas suas ações, pensamentos e sentimentos (Aguiar, 2001).

No processo de análise, o primeiro passo foi a leitura das entrevistas e a categorização das respostas. Algumas categorias foram: projeto profissional, formação profissional e processo de trabalho na ESF. Em seguida, procurou-se articular as categorias entre si e com os temas estudados.

O projeto de pesquisa foi aprovado pela secretaria de saúde do município do interior de Mato Grosso do Sul e pelo Comitê de Ética em Pesquisa da Universidade Federal de Mato Grosso do Sul, sob o número 680, de abril de 2006.

\section{Caracterização dos participantes e desvelamento do projeto profissional}

Os participantes eram relativamente jovens (média de idade entre todos os participantes era de 34 anos e, especificamente, dos enfermeiros, 25 anos) e estavam, em grande parte, no primeiro emprego (sete enfermeiros e dois 
cirurgiões-dentistas: D-2, D-3, E-1, E-2, E-3, E-4, E-5, E-8 e E-10). Isto, por sua vez, justifica o tempo relativamente pequeno de inserção na ESF (54\% dos participantes estavam com vínculo funcional de até dois anos). Outro motivo para essa inserção recente na área pode ser a excessiva rotatividade de profissionais (apenas três profissionais - cirurgiões-dentistas - estavam na função desde a implantação da ESF no município). Outros estudos destacam a alta rotatividade na área: no município de São Paulo (SP), por exemplo, a rotatividade de médicos na ESF foi de 37\%, no período de julho de 2004 a junho de 2005 (Campos e Malik, 2008), enquanto no Vale do Taquari (RS) foi de 64,5\% no ano de 2005 (Medeiros et al., 2010). Índices elevados, se considerarmos como referência temporal o percentual de $0 \%$ a $25 \%$ ao ano como adequado, entre $25 \%$ e $50 \%$ ao ano como ruim e acima de $50 \%$ um índice crítico (Campos e Malik, 2008).

De acordo com a psicologia sócio-histórica, para a construção consciente de um projeto profissional é preciso ampliar o conhecimento de si como um ser particular, mas ao mesmo tempo histórico e social (Bock e Aguiar, 1995). Isso significa ter conhecimento de si e de como essa identidade foi construída ao longo do tempo e das relações estabelecidas, assim como ter um conhecimento crítico sobre a realidade e o mundo do trabalho.

Com base na análise dos dados desta pesquisa, percebe-se que o principal motivo de escolha da ESF como campo de atuação profissional está relacionado ao surgimento de uma oportunidade de trabalho e não como consequência do estabelecimento consciente de um projeto profissional.

Quando foi pra contratar os dentistas, surgiu a oportunidade de eu ser chamada. Aí, como eu estava parada, o primeiro emprego, eu entrei no PSF. Não tinha trabalhado em lugar nenhum ainda (D-2).

Eu saí da faculdade em dezembro, dia 3 de janeiro eu já tava trabalhando aqui. Não foi bem uma escolha, não, foi o que surgiu (...) foi muito rápido (E-3).

(...) sem ser hospital, a primeira oportunidade [de emprego], lógico que eu ia agarrar, mas se surgisse PSF eu ia gostar, e foi a primeira proposta de emprego que eu tive também (E-4).

No caso de E-4, o campo hospitalar aparece como interesse inicial, somente depois cita a ESF como uma possibilidade de inserção, a qual representou sua primeira proposta de trabalho. Tal motivo de inserção pode estar relacionado à ampliação de vagas na área e à adequação da formação e do projeto profissional ao mercado de trabalho.

O número de equipes no país até agosto/2011 alcançou 32 mil e 21.038 equipes de Saúde Bucal (Brasil, 2011). Embora as condições de trabalho pro- 
postas a esses profissionais não sejam satisfatórias - contratos de trabalho temporários e, consequentemente, a instabilidade do vínculo trabalhista, a não garantia de direitos trabalhistas e a insegurança provocada no profissional (Rocha e Trad, 2005) -, a ESF tornou-se uma oportunidade de trabalho dada a expansão do número de vagas.

Tal expansão pode alterar a configuração de expectativas profissionais e inserção no mercado de trabalho, como é possível notar na área de odontologia. Com base em estudo realizado com egressos do curso de odontologia da Universidade Federal do Ceará (Pinheiro et al., 2011), os principais campos de atuação profissional são a ESF (41,4\% dos profissionais) e, em segundo lugar, clínicas privadas $(36,2 \%)$. A respeito das expectativas profissionais, Matos e Tenório (2011) identificaram que a ESF faz parte dos planos dos profissionais a curto prazo; a médio e longo prazos há uma grande expectativa de possuírem consultório particular.

Contudo, nota-se por meio do estudo de Fernandes Neto e colaboradores (2006) que muitos cirurgiões-dentistas têm deixado a prática liberal e se dirigido à Saúde Pública, juntando-se aos recém-formados na luta pela oportunidade de emprego devido à demanda de profissionais e às vagas oferecidas no mercado de trabalho. Nesse município onde foi realizada a pesquisa, dois cirurgiões-dentistas (D-5 e D-6) abandonaram a prática liberal e dedicam-se exclusivamente à Saúde Pública: “Hoje, (em serviço) particular, eu não trabalho mais, só mesmo serviço público" (D-5).

Dentre os participantes, 13 (nove enfermeiros, três dentistas e um médico) atuam exclusivamente na Saúde da Família. Os profissionais que trabalham em mais de um local geralmente estão vinculados a consultórios particulares.

$\mathrm{O}$ que se percebe aqui é uma adequação do projeto profissional à necessidade do mercado de trabalho, já que esses novos profissionais atuam na esfera pública, mesmo que ainda desejem atuar no setor privado (Ferreira, Ferreira e Freire, 2013). Araújo e Veras (2009, p. 54) destacam em seu estudo essa transitoriedade dos profissionais pela ESF: “a maioria dos profissionais de saúde que trabalham no PSF almejam por outras oportunidades de empregos mais seguros e rentáveis, fazendo do Programa de Saúde da Família apenas um alicerce na sua vida profissional".

O problema de se estabelecer um projeto profissional com base exclusivamente ou principalmente no mercado de trabalho é escolher uma atividade que não proporcione desenvolvimento/satisfação pessoal e, ao mesmo tempo, não produza resultados positivos à população e ao serviço ao qual está vinculado.

No entanto, considerando-se as características do mercado de trabalho na contemporaneidade (informalidade, terceirização de serviços, flexibilização dos vínculos de trabalho, redução do emprego estável e do emprego assalariado) (Valore e Selig, 2010), é possível entender o motivo de as escolhas profissionais terem de se acomodar às oportunidades de trabalho existentes. 
Severino (2009, p. 259) destaca que a lógica do mercado é uma lógica utilitarista, instrumental, que valoriza a competição e o individualismo, incentivando "uma vista medíocre e egoísta da vida social e de sua participação nela".

Os únicos profissionais que apresentaram como motivo para a inserção na ESF a afinidade com a área foram os enfermeiros (E-1, E-2, E-4, E-8, E-9 e E-10): “Como eu vi o programa [durante a graduação], eu conhecia, fazia estágio lá, gostava do programa, achava interessante" (E-8).

Os enfermeiros e apenas um cirurgião-dentista (D-1) afirmaram que durante a graduação tiveram alguma formação para atuação na Saúde da Família.

\section{Influência da formação profissional}

A escolha da Saúde da Família por seis enfermeiros devido à afinidade com a área pode caracterizar um tipo de influência educacional, uma vez que foram principalmente eles que, durante a graduação, tiveram formação sobre a Saúde da Família. Essa formação na área possivelmente está relacionada às transformações que vêm ocorrendo nos cursos da área da saúde, em razão das Diretrizes Curriculares Nacionais (DCNs), já que foram os mais jovens que a tiveram (oito enfermeiros e um cirurgião-dentista).

A partir da década de 1990, com a Lei de Diretrizes e Bases da Educação Nacional (Brasil, 1996), foram elaboradas as DCNs para os cursos da área da saúde aprovadas entre 2001 e 2004 (Brasil, 2001b, 2001c, 2002b), que se caracterizam como "padrão geral de orientação para a elaboração dos currículos e dos projetos políticos pedagógicos que devem ser adotados por todas as instituições de ensino superior (IES)" (Pereira e Lages, 2013, p. 324).

Apesar da crítica que se faz em relação ao referencial teórico-epistemológico adotado nas DCNs (Pereira e Lages, 2013), admite-se que “a instituição das diretrizes vem provocando mudanças na estruturação curricular de diversos cursos e nos projetos das instituições de ensino em saúde no cenário nacional" (Pereira e Lages, 2013, p. 325), já que se menciona a necessidade da formação do profissional generalista, crítico, reflexivo, com ampla visão sobre o processo saúde-doença, compreensão da integralidade da pessoa e do processo de cuidado e, principalmente, para atuação no Sistema Único de Saúde de acordo com as demandas existentes (Carvalho e Ceccim, 2008). Ainda assim, considerando que estamos em uma fase de transição, nos projetos educacionais e de saúde, o modelo biomédico é hegemônico, sendo a doença caracterizada pela dimensão biológica e o enfoque curativo predominante (Ceccim e Feuerwerker, 2004).

Com base nos dados obtidos nesta pesquisa, vale a pena destacar algumas defasagens teórico-técnicas observadas na graduação, como, por exemplo, a fragmentação do conhecimento, a restrição de cenários de atuação e o ensino deficitário, de forma geral. 
O modo como o conhecimento é sistematizado, de forma fragmentada e sem articulação, às vezes dificulta o entendimento da totalidade da ciência e da profissão. A distância entre teoria e prática, separando-as em momentos distintos, tanto pode prejudicar a formação como causar desinteresse ou desistência do curso, como comentado por E-3:

Olha, no começo eu não gostava. Eu achei muito teórico (...) nos dois primeiros anos era muita teoria, não tinha técnica. Ele [curso] era dividido: dois anos só teoria, a gente foi ver mesmo prática a partir do terceiro ano, só que o quarto ano lá de graduação, a gente não tem aula, não tem mais teoria, lá [naquele curso] é só estágio (E-3).

Neste outro relato, o profissional destaca uma possível tendência da fragmentação do conhecimento ou excessiva especialização do cirurgião-dentista para a sua atuação profissional:

Porque, eu sempre pensei, eu acho assim, que a especialização te centraliza muito só em uma área. Eu acho, eu enxergo a odontologia como um todo. Eu não consigo enxergar como uma área assim específica. Mas enxergar o paciente não como uma boca, né?, como (risos) um ser humano. Porque o dentista tem muito essa tendência, sabe, de ficar ali, de [considerar que] você não é um paciente, você é uma boca (D-6).

Essa fragmentação é decorrente, por um lado, da influência capitalista que divide trabalho intelectual e manual (Sonzogno, 2004) e, por outro, de um modelo positivista de ciência que compartimenta o saber em disciplinas isoladas, desarticula o núcleo básico do profissional e não integra o aprendizado às necessidades sociais (Silva, 2004).

Não, não teve estágio (em Saúde Pública). Só foi matéria mesmo. Não foi nem meio semestre. Pegou uma psicóloga para dar uma noção geral de Saúde Coletiva (D-2).

Em algumas instituições, uma disciplina do núcleo básico é oferecida a alunos de vários cursos ao mesmo tempo, a fim de evitar duplicação de recursos. Como consequência disso, pode-se potencializar um trabalho interdisciplinar, mas perder a especificidade de cada curso.

Outro dado que pode contribuir para essa deficiência na formação é a falta de incentivo ao docente para as atividades de ensino, especialmente na graduação. Nas instituições públicas, o mérito do professor é avaliado pela produção acadêmica (que normalmente está vinculada à pesquisa) e não pelas atividades de ensino. Nas instituições privadas, a carga horária estabelecida no contrato dos professores não inclui planejamento e avaliação das atividades didáticas, contando apenas o tempo em sala de aula (Silva, 2004). 
A fragmentação do conhecimento também é percebida na inadequação dos cenários de atuação ao ensino e à assistência:

Quando a gente chega aqui [ESF], é totalmente diferente do que eles [professores] deram lá. Então eu acho que faltou eles [professores] estarem trazendo a gente mais para a realidade, não estar pegando aquele PSF que é modelo e dando pra gente. Eu acho que eles tinham que pegar o modelo e um que está deficiente (E-5).

Bagnato e Cocco (2002, p. 442), em estudos sobre a licenciatura em enfermagem, destacam que "é imprescindível trabalhar diferentes aspectos da realidade, inclusive a maneira como os sujeitos educativos pensam a realidade".

Para Feuerwerker (2003, p. 26), é fundamental a diversificação de cenários de ensino ao longo da formação acadêmica, "de modo que os estudantes tenham a oportunidade de aprender e trabalhar em todos os espaços em que se dá a atenção à saúde".

Em pesquisa realizada por Sanchez, Drumond e Vilaça (2008), alunos do curso de odontologia de duas faculdades foram entrevistados a fim de identificar seus conhecimentos, habilidades e desejos de trabalhar na Saúde da Família. O curso que oferecia estágio supervisionado em um internato rural desenvolveu nos alunos consciência política e humanizadora, além de promover uma visão mais ampliada sobre a Saúde da Família.

Albuquerque e colaboradores (2008), em seu estudo sobre a integração ensino-serviço, destacam que o usuário deve ser o ponto central dessa discussão, de forma que todos os olhares contribuam para o desenvolvimento do cuidado dele. Esses locais onde os estudantes são inseridos caracterizam-se como espaços para reflexão e problematização da prática, para que, dessa forma, novos profissionais e novos cuidados de saúde sejam constituídos de acordo com a demanda existente.

Além disso, destaca-se a defasagem de cursos superiores vinculados à política de expansão do governo federal:

Senti falta de professor qualificado. Às vezes, falta de material, falta de infraestrutura, meu curso lá era novo, igual alguns são, então faltou alguma coisa (E-8).

Esses cursos de expansão no ensino superior federal foram estabelecidos desde 2003. A primeira etapa compreendeu o período de 2003 a 2007 e teve como principal objetivo interiorizar o ensino público federal (Weska et al., 2012).

Embora o exemplo (relato de E-8) esteja relacionado à política de expansão do ensino superior público, o que ocorreu, de fato, foi um aprofundamento da privatização da educação superior no país, principalmente no período de 1996 a 2004, no qual "cerca de 90\% das instituições brasileiras de ensino superior são privadas, sendo responsáveis por $70 \%$ das matrí- 
culas neste nível de ensino" (Paula, 2009, p. 79). Assim, a participação do ensino público superior no total de cursos de graduação presenciais passou de 44,8\% em 1996 para 29,6\% em 2006. Percebe-se, neste período, de maneira geral, a vinculação do sistema educacional às regras do mercado, ou seja, a educação como um serviço ou bem que visa atender aos interesses mercantis e não como bem público de socialização do conhecimento e formação crítica do sujeito (Sguissardi, 2008; Segenreich e Castanheira, 2009).

Nem as DCNs conseguiram escapar a essa lógica. A pedagogia das competências - referencial teórico-epistemológico que orienta as DCNs - é fundamentada filosoficamente na "tríade competência-qualificação-adaptabilidade, que estrutura um modelo de formação capacitado a atender as exigências do mercado" (Pereira e Lages, 2013, p. 326). Com base nessa análise crítica, os autores defendem a pedagogia histórico-crítica ${ }^{8}$ para a formação em saúde como um referencial coerente aos pressupostos da Reforma Sanitária Brasileira:

Para além da competência técnica, é necessário que os sujeitos egressos dos referidos processos de formação tenham a oportunidade do engajamento político, do questionamento dos problemas da ordem social vigente e da viabilização da construção de uma práxis histórica de reestruturação social a partir de sua atuação profissional (Pereira e Lages, 2013, p. 330).

A coerência entre a formação e o que se espera da atuação profissional é indispensável para atender às necessidades em saúde. Por esta razão, a qualidade da formação em saúde deve estar relacionada ao papel social e político do trabalho em saúde (Carvalho e Ceccim, 2008).

Evitar a armadilha de informar pensando que se está formando talvez seja um dos primeiros passos em busca de uma formação crítica. Formar para a mudança exige questionamento do que está instituído (Ceccim e Feuerwerker, 2004), o que torna essa tarefa difícil.

De acordo com Severino (2009), a universidade tem uma responsabilidade social de assegurar a formação integral dos estudantes, ou seja, ela tem

um compromisso ético-político: o profissional a ser formado é antes de tudo um ser humano, que precisa tornar-se sensível à dignidade humana bem como um cidadão que precisa se comprometer com a democratização das relações sociais, dotando-se de uma nova consciência social. E pouco importa qual seja sua área de profissionalização (Severino, 2009, p. 262).

A reflexão sobre essas questões pode contribuir não apenas para a formação crítica do cidadão como também para a construção mais consciente de um projeto profissional. 


\section{Implicações para a atuação profissional}

A atuação dos profissionais da ESF tem papel imprescindível na consolidação desse novo modelo de atenção à saúde (Ribeiro et al., 2008). Ellery, Pontes e Loiola (2013) identificaram em pesquisa com profissionais e residentes da ESF saberes e práticas que integram o campo comum de atuação das equipes da ESF, incluindo o NASF. Dentre estes, destacamos: trabalhar em equipe; construir um plano de ação nos territórios, em conjunto com a população, suas organizações sociais e demais instituições que atuam no território; desenvolver ações de educação em saúde; intervir em condições sociais da clientela; e adotar uma postura de acolhimento e estabelecimento de vínculo e responsabilização com usuários e trabalhadores da saúde.

Contudo, Gil (2005, p. 497) observou em sua pesquisa que ainda existe "muita indefinição quanto às competências e práticas profissionais esperadas para a atuação na atenção básica e, em especial, na saúde da família". Assim, verifica-se que primeiro ocorre a inserção no campo e, em seguida, a formação - isso para os profissionais que apresentam interesse pela área, que são principalmente os de enfermagem.

Dentre os participantes desta pesquisa, a maior procura por cursos de especialização é de enfermeiros (seis profissionais com especialização em Saúde da Família concluída ou em andamento). Entre cirurgiões-dentistas e médicos, apenas um médico está inserido em programa de pós-graduação em Saúde da Família; os outros não têm especialização ou residência nem em Saúde Pública.

Alguns dificultadores apresentados pelos profissionais para a inserção em cursos de especialização são a falta de incentivo da administração municipal na formação profissional e a baixa valorização da área, sendo este último aspecto uma percepção dos profissionais de medicina e odontologia.

Em relação à falta de incentivo, Gil (2005) ressalta que a fragilidade nos vínculos empregatícios tem influência determinante nessa questão, pois a estabilidade no trabalho pode aumentar a possibilidade de se investir mais na formação, tornando-a consistente e duradoura.

O próprio curso introdutório, de responsabilidade do município e do estado, previsto na Política Nacional de Atenção Básica (Brasil, 2006), que estabelece a organização do trabalho na Atenção Básica e deve anteceder as atividades da equipe, foi oferecido aos profissionais de nível superior apenas no momento em que foi implantada a ESF nesse município (final da década de 1990). É necessário ressaltar que, das quatro equipes iniciais que participaram do processo de capacitação, apenas dois profissionais (D4 e D5) estiveram presentes e continuam vinculados à ESF. Alguns enfermeiros relataram que participaram, no momento de ingresso na ESF do município, de um curso direcionado aos agentes comunitários de saúde. Mesmo assim, destacam que o cumprimento do curso tinha objetivo burocrático e 
não necessariamente formativo: “Teve um curso básico. A gente foi junto com os agentes (...) mas foi muito rápido, era mais pra implantar logo, senão perdia o programa" (E-1).

Além disso, nenhum profissional afirmou participar de atividades de educação permanente - embora a Política Nacional de Atenção Básica (Brasil, 2006, p. 11) tenha como um de seus fundamentos "valorizar os profissionais da saúde por meio do estímulo e do acompanhamento constante de sua formação e capacitação". É de competência da esfera municipal "estimular e viabilizar a capacitação e a educação permanente dos profissionais da equipe" (Brasil, 2006, p. 13); de competência estadual e federal "disponibilizar instrumentos técnicos e pedagógicos que facilitem o processo de formação/capacitação" (Brasil, 2006, p. 15-16); e de competência federal "estabelecer diretrizes nacionais" (Brasil, 2006, p. 16).

De maneira geral, percebe-se que a formação na área, principalmente os que têm pós-graduação, influencia no desempenho satisfatório das atividades, à medida que eles têm uma visão mais ampla das atribuições profissionais e dos princípios da Política Nacional de Atenção Básica (Brasil, 2006), mesmo que não seja possível a concretização de todos os projetos em razão das limitações impostas pela administração municipal.

Terminei minha pós, fiquei mais por dentro, agora a gente não chama mais de programa. É estratégia. É maravilhoso se funciona adequadamente (...) se você tem um gestor que te dê apoio, se você tem um prefeito, sabe, você tem que ter tudo integrado, pra funcionar na unidade da saúde; não adianta você (ênfase ao dizer você) nadar, nadar, nadar, nadar; você morre na praia (E-1).

Nos casos em que a formação para a ESF foi insuficiente durante a graduação e os motivos para a inserção nesta área foram exclusivamente os aspectos financeiros ou oportunidade de trabalho na área, nota-se que, principalmente entre cirurgiões-dentistas e médicos, a atuação encontra-se limitada em virtude do desconhecimento e da insatisfação com a área de trabalho.

Lá [no consultório] é uma casa pra mim. Além do que, com certeza, eu sei fazer muito [mais] de oftalmologia do que atendimento de PSF. Então tudo que você faz com mais firmeza, você se sente melhor fazendo (M-5).

Eu só faço as visitas quando os agentes julgam, depende da pressa, da urgência e da quantidade. Porque não adianta eu deixar de atender aqui pra atender uma pessoa só (M-5).

Como a inserção na ESF, na maioria dos casos, não compõe um projeto de vida profissional e como, também, não existem incentivos e políticas de 
formação e qualificação para esse profissional, é possível que ele não perceba a diferença entre a atuação profissional nos diferentes contextos:

Não tem [educação permanente] porque não é necessário. O que vai pesar isso na balança? Agora, se tivesse, a gente tinha que fazer, né? Praticamente não contribuiu em nada [capacitação sobre ESF]. Porque a gente já sabe tudo o que tem que fazer (D-7).

Nesse depoimento, "saber tudo o que tem que fazer" pode estar relacionado aos aspectos técnicos e tradicionais da profissão. No entanto, as atribuições dos profissionais vinculados à ESF não são as mesmas dos contextos clínicos e não se restringem à realização do diagnóstico e tratamento/reabilitação.

Além das atribuições específicas, são atribuições de todos os profissionais, por exemplo, "participar das atividades de planejamento e avaliação das ações da equipe; promover a mobilização e a participação da comunidade, buscando efetivar o controle social" (Brasil, 2006, p. 43).

Entretanto, em alguns casos (D-1, D-6, E-3, E-4 e M-2), observou-se que a experiência na ESF proporcionou uma mudança de interesse em relação às expectativas iniciais. Ou seja, apesar de a ESF não ter sido inicialmente um projeto profissional desses participantes e apesar das deficiências no processo de formação e inserção no trabalho, eles relataram o interesse em continuar trabalhando nessas unidades em razão de, entre outros motivos, estarem satisfeitos com a atividade.

Na época [que concluiu a graduação] era [interesse] hospitalar, tanto é que depois eu fui fazer pós, eu fui fazer em cardiologia porque eu queria hospitalar, mas agora, hoje eu já prefiro PSF (E-3).

Todo mundo falando [que PSF era ruim], daí eu descobri (fala com ênfase) que elas estavam falando com medo de perder o lugar. Não era assim [ruim]. Então, eu adorei. Eu fui conhecer, eu fui fazer o curso (D-1).

Considerando que a identidade é constituída com base nas relações sociais e na atividade desempenhada em um contínuo movimento de transformação, um novo projeto profissional poderá ser construído de acordo com as condições concretas de existência.

Trabalhei um tempo no hospital lá, eu gostei, eu gosto também, gostava, mas eu gostei mais do PSF (E-9).

Hoje, o consultório para mim é... é um complemento, que eu gosto muito de estar trabalhando lá. Mas eu de repente, eu perdi um pouco dessa identidade de profissional liberal, sabe? (D-6). 
Fui fazer [especialização] mais laboratorial pra não ter mais contato com o paciente, porque é duro. Estou fazendo agora; é completamente diferente. Eu achei que eu nem ia gostar (...) Você acaba criando um certo vínculo e acaba se especializando mais. Tanto que eu quero sair pra fora (...) fazer doutorado, fazer em cima de ensino de família (M-2).

Como afirma Bock (2002, p. 180), “a subjetividade, incluindo habilidades e interesses, é forjada na dialética das relações sociais internalizadas. Portanto, a subjetividade é histórica e por isso passível de transformações".

\section{Considerações finais}

Com base na análise dos dados desta pesquisa, foi possível constatar que a ESF está sendo procurada pelos profissionais, principalmente, em razão de ser uma oportunidade de emprego. Há, no início, pouco conhecimento ou identificação com seus princípios e objetivos (especialmente entre cirurgiões-dentistas e médicos), o que pode desencadear atividades incoerentes à proposta estabelecida, como, por exemplo, uma prática centrada em consultas. Deve-se destacar, no entanto, que o próprio município incentiva essa prática, fornecendo aumento salarial de acordo com a produtividade do médico, entendendo 'produtividade' como realização de mais procedimentos.

Apesar da ênfase dada ao processo de formação na Política Nacional de Atenção Básica (Brasil, 2006), nesse município não se tem oferecido o treinamento inicial, nem se viabilizado a educação permanente, tampouco incentivado a especialização na área. Mesmo assim, alguns profissionais demonstraram interesse pela área de atuação após a experiência na Saúde da Família, o que indica a possibilidade de alteração e mobilização de interesses ao longo da trajetória profissional.

Ressalta-se então a importância dos processos educativos como uma forma de incentivar e favorecer a atuação e o compromisso dos profissionais com o SUS e a Saúde da Família. Além disso, sugere-se a orientação profissional como atividade pertinente a ser oferecida tanto àqueles que estão escolhendo a profissão ou área de atuação profissional como, também, àqueles que já estão inseridos no mercado de trabalho. 


\section{Colaboradores}

Rosimeire Aparecida Manoel realizou a pesquisa com os enfermeiros; Fernanda Márcia de Azevedo Gomes, com os médicos; Katiuska Fabiana da Silva, com os cirurgiões-dentistas; Denise Stefanoni Combinato orientou todas as pesquisas. Para a elaboração deste artigo, as autoras participaram igualmente de todas as etapas.

Resumen El objetivo del estudio fue analizar los factores determinantes para la elección de la Estrategia de la Salud de la Familia como campo de actuación profesional, con el fin de comprobar la influencia de la formación académica y sus implicaciones. Fueron entrevistados individualmente, entre octubre de 2006 y febrero de 2007, 22 profesionales de nivel superior (cirujanos dentistas, enfermeros y médicos) de los equipos de la Salud de la Familia de un municipio de Mato Grosso do Sul (Brasil). Las entrevistas fueron grabadas, transcritas y analizadas de acuerdo con el marco teórico y metodológico de la psicología socio-histórica. Se observó que la opción profesional para la Estrategia de la Salud de la Familia no ocurrió en forma reflexiva y crítica, sino que fue influenciada principalmente, por la expansión del área y por las ofertas de empleo, lo que puede comprometer su actividad profesional. La sugerencia es invertir en procesos educativos como una forma de incentivar y favorecer la actuación y el compromiso de los profesionales con el Sistema Único de Salud y, sobre todo, con la Salud de la Familia.

Palabras clave Salud de la Familia, psicología, orientación vocacional. 


\section{Notas}

1 Associação de Ensino e Cultura de Mato Grosso do Sul, Três Lagoas, Mato Grosso do Sul, Brasil.

Doutoranda em Saúde Coletiva pela Faculdade de Medicina de Botucatu.

$<$ rosemary_psi@hotmail.com>

Correspondência: Rua Eça de Queiroz, 94, Ilha Bela, CEP 15385-000, Ilha Solteira, São Paulo, Brasil.

2 Instituto Tecnológico de Aeronáutica, São José dos Campos, São Paulo, Brasil.

Doutora em Saúde Coletiva pela Faculdade de Medicina de Botucatu.

$<$ denisecombinato@hotmail.com>

3 Mestre em Psicologia pela Universidade Federal de São João Del-Rei, Minas Gerais, Brasil.

$<$ fmazevedogomes@yahoo.com.br $>$

4 Especialista em Saúde da Família (Residência Profissional) pela Faculdade de Medicina de Marília, Marília, São Paulo, Brasil.

$<$ katiuska_fabiana@hotmail.com>

${ }^{5}$ As letras escolhidas referem-se a cirurgião-dentista (D), enfermeiro (E) e médico (M).

${ }^{6}$ As traduções no nome desse autor apresentam diferentes formas: Vigotski, Vygotsky, Vuigotskij, dentre outras. Neste artigo, utilizou-se Vigotski quando o autor é citado sem referência a uma obra específica; quando vinculado a uma obra, manteve-se a grafia da publicação.

7 Trecho traduzido de: “El análisis del proceso, y no de la cosa; el análisis, que descubre el enlace y la relación dinámico-causal real, y no el análisis que descompone los rasgos externos del proceso; por lo tanto un análisis explicativo y no descriptivo y, por fin, el análisis genético, que regresa al punto de partida y restablece todos los procesos de desarrollo de una determinada forma, que, en su aspecto presente, ya aparece como una fosilización psicológica" (Vuigotskij, 1987, p. 113).

8 A pedagogia histórico-cultural e a psicologia sócio-histórica ou histórico-cultural se articulam nas suas bases epistemológicas e pressupostos: “Tanto para a psicologia histórico-cultural quanto para a pedagogia histórico-crítica, por assentarem-se no materialismo histórico-dialético, isto é, no marxismo, o homem é um ser social, cujo desenvolvimento condiciona-se pela atividade que o vincula à natureza" (Martins, 2011, p. 212). E acrescenta: “Considerando então que a humanidade não 'nasce' nas pessoas a partir delas mesmas, mas resulta da humanidade objetivada e disponibilizada às suas internalizações, a psicologia histórico-cultural e a pedagogia histórico-crítica não são indiferentes à análise das condições objetivas que, em uma sociedade de classes, reservam para diferentes indivíduos condições desiguais de humanização" (Martins, 2011, p. 213). 


\section{Referências}

AGUIAR, Wanda M. J. A pesquisa em psicologia sócio-histórica: contribuições para o debate metodológico. In: BOCK, Ana M. B.; GONÇALVES, Maria G. M.; FURTADO, Odair (Org.). Psicologia sócio-histórica: uma perspectiva crítica em psicologia. São Paulo: Cortez, 2001. p. 129-158. cap. 7.

AKERMAN, Marco; FEUERWERKER, Laura. Estou me formando (ou me formei) e quero trabalhar: que oportunidades o sistema de saúde me oferece na saúde coletiva? Onde posso atuar e que competências preciso desenvolver? In: CAMPOS, Gastão W. S. et al. (Org.). Tratado de Saúde Coletiva. 2. ed. São Paulo: Hucitec; Rio de Janeiro: Editora Fiocruz, 2008. p. 171-88. cap. 6.

ALBUQUERQUE, Verônica S. et al. A integração ensino-serviço no contexto de mudança na formação superior dos profissionais de saúde. Revista Brasileira de Educação Médica, Rio de Janeiro, v. 32, n. 3, p. 356-362, jul./set., 2008.

ANDRADE, Luiz O. M.; BUENO, Ivana C. H.; BEZERRA, Roberto $C$. Atenção primária à saúde e Estratégia Saúde da Família. In: CAMPOS, Gastão W. S. et al. (Org.). Tratado de Saúde Coletiva. 2. ed. São Paulo: Hucitec; Rio de Janeiro: Editora Fiocruz, 2008. p. 783-836. cap. 25.

ARAÚJO, Maria F. S.; VERAS, Klênia F. O. Processo e precarização do trabalho no Programa de Saúde da Família. CAOS: Revista Eletrônica de Ciências Sociais, n. 14, set. 2009.

BAGNATO, Maria H. S.; COCCO, Maria I. M. Memória educativa e a tessitura de conceitos educacionais: experiência vivenciada na licenciatura em enfermagem. Revista Latino-Americana de Enfermagem, Ribeirão Preto, v. 10, n. 3, p. 439-445, maio/jun. 2002.

BOCK, Ana M. B.; AGUIAR, Wanda M. J. Por uma prática promotora de saúde em orientação vocacional. In: BOCK, Ana M. B. et al. (Org.). A escolha profissional em questão. São Paulo: Casa do Psicólogo, 1995. p. 9-23.
BOCK, Silvio D. Orientação profissional: a abordagem sócio-histórica. 2. ed. São Paulo: Cortez, 2002.

BRASIL. Lei n. 9.394 de 20 de dezembro de 1996. Estabelece as Diretrizes e Bases da Educação Nacional. Diário Oficial da República Federativa do Brasil, Poder Executivo, Brasília, DF, 23 dez. 1996. Seção 1, p. 27.839.

BRASIL. Ministério da Saúde. Guia prático do programa saúde da família. Brasília, $\mathrm{DF}$, 2001a. Disponível em: <http://189.28.128. 100/dab/docs/publicacoes/geral/guia_ pratico_saude_familia_psf1.pdf $>$. Acesso em: 15 nov. 2005

BRASIL. Resolução CNE/CES n. 03, de 7 de novembro de 2001. Institui as diretrizes curriculares nacionais para curso de graduação em enfermagem. Diário Oficial da República Federativa do Brasil, Poder Executivo, Brasília, DF, 7 nov. 2001 b. Seção 1, p. 37.

BRASIL. Resolução CNE/CES n. 04, de 7 de novembro de 2001. Institui as diretrizes curriculares nacionais para curso de graduação em medicina. Diário Oficial da República Federativa do Brasil, Poder Executivo, Brasília, DF, 7 nov. 2001c. Seção 1, p. 38.

BRASIL. Ministério da Saúde. Programa saúde da família: equipes de saúde bucal. Brasília, DF, 2002a. 24p. (Série C. Projetos, Programas e Relatórios). Disponível em: <http:// dtr2001.saude.gov.br/editora/produtos/ livros/popup/02_1064.htm >. Acesso em: 16 dez. 2011.

BRASIL. Conselho Nacional de Educação. Câmara de Educação Superior. Resolução CNE/CES n. 3, de 19 de fevereiro de 2002. Institui as diretrizes curriculares nacionais para curso de graduação em odontologia. Diário Oficial da República Federativa do Brasil, Poder Executivo, Brasília, DF, 19 nov. 2002b. Seção 1, p. 10.

BRASIL. Ministério da Saúde. PNAB: Política Nacional de Atenção Básica. Secretaria 
de Atenção à Saúde. Departamento de Atenção Básica. Brasília, DF, 2006. (Série Pactos pela Saúde 2006, v. 4).

BRASIL. Ministério da Saúde. Secretaria de Atenção à Saúde. Departamento de Atenção Básica. Saúde Bucal. Brasília, DF, 2008a. 92p. (Cadernos de Atenção Básica, 17). Disponível em: <http://dtr2001.saude.gov.br/ editora/produtos/livros/popup/saude_ bucal.html>. Acesso em: 16 dez. 2011.

BRASIL. Portaria n. 154, de 24 de janeiro de 2008. Cria os Núcleos de Apoio à Saúde da Família - NASF. Diário Oficial da República Federativa do Brasil, Poder Executivo, Brasília, DF, 24 jan. 2008b. Seção 1, p. 47.

BRASIL. Ministério da Saúde. Departamento de Atenção Básica. Histórico de Cobertura do PSF. Situação de implantação de equipes de Saúde da Familia, saúde bucal e agentes comunitários de saúde: Brasil, Agosto 2011. Departamento de Atenção Básica. Ministério da Saúde, 2011. Disponível em: <http:// dab.saude.gov.br/abnumeros.php\#historico $>$. Acesso em: 27 out. 2011.

BRASIL. Ministério da Saúde. Departamento de Atenção Básica. Evolução do credenciamento e implantação da estratégia Saúde da Família. Nota técnica. Brasília: Ministério da Saúde, 2014. Disponível em: <http://dab. saude.gov.br/historico_cobertura_sf.php $>$. Acesso em: 16 jul. 2014.

CAMPOS, Cláudia V. A.; MALIK, Ana M. Satisfação no trabalho e rotatividade dos médicos do Programa de Saúde da Família. Revista de Administração Pública, Rio de Janeiro, v. 42, n. 2, p. 347-368, mar./abr. 2008.

CARVALHO, Yara M.; CECCIM, Ricardo B. Formação e educação em saúde: aprendizados com a saúde coletiva. In: CAMPOS, Gastão W. S. et al. (Org). Tratado de saúde coletiva. 2. ed. São Paulo: Hucitec; Rio de Janeiro: Editora Fiocruz, 2008. p. 137-170. cap. 5.

CECCIM, Ricardo B.; FEUERWERKER, Laura C. M. Mudança na graduação das profissões de saúde sob o eixo da integralidade. Caderno de Saúde Pública, Rio de Janeiro, v. 20, n. 5, p. 1.400-1.410, set./out. 2004.

ELLERY, Ana E. L.; PONTES, Ricardo J. S.; LOIOLA, Francisco A. Campo comum de atuação dos profissionais da Estratégia Saúde da Família no Brasil: um cenário em construção. Physis: Revista de Saúde Coletiva, Rio de Janeiro, v. 23, n. 2, p.415-437, 2013. Disponível em: <www.scielo.br/pdf/physis/v23n2/ v23n2a06.pdf $>$. Acesso em: 14 jan. 2014.

FERNANDES NETO, Alfredo J. et al. Odontologia. In: HADDAD, Ana E. et al. (Org.). A trajetória dos cursos de graduação na área da saúde: 1991-2004. Brasília: Instituto Nacional de Estudos e Pesquisas Educacionais Anísio Teixeira, 2006. p. 382-409.

FERREIRA, Maria P.; FERREIRA, Aline P.; FREIRE, Maria C. M. Mercado de trabalho na odontologia: contextualização e perspectivas. Revista de Odontologia da Unesp, Araraquara, v. 42 , n. 4, p. 304-309, 2013. Disponível em: <www.scielo.br/pdf/rounesp/ v42n4/11.pdf>. Acesso em: 14 jan. 2014.

FEUERWERKER, Laura. C. M. Educação dos profissionais de saúde hoje: problemas, desafios, perspectivas e as propostas do Ministério da Saúde. Revista da Abeno, Londrina, v. 3, n. 1, p. 24-27, 2003.

GIL, Célia R. R. Formação de recursos humanos em saúde da família: paradoxos e perspectivas. Cadernos de Saúde Pública, Rio de Janeiro, v. 21, n. 2, p. 490-498, mar./abr. 2005.

LUNA, Iuri N. Realização pessoal e realização coletiva: a responsabilidade da orientação profissional na construção da identidade profissional. In: MELO-SILVA, Lucy L. (Org.). Arquitetura de uma ocupação: orientação profissional - teoria e técnica. São Paulo: Vetor, 2003. p. 91-96. cap. 6.

MARTINS, Lígia M. O desenvolvimento do psiquismo e a educação escolar: contribuições à luz da psicologia histórico-cultural e da pedagogia histórico-crítica. 249f. Tese (Livre-docência). Faculdade de Ciências, Unesp, Bauru, 2011. 
MATOS, Mariangela S.; TENÓRIO, Robinson M. Expectativas dos estudantes de odontologia sobre o campo de trabalho odontológico e o exercício profissional. Revista Brasileira de Pesquisa em Saúde, Vitória, v. 13, n. 4, p. 10-21, 2011. Disponível em: $<$ http://periodicos.ufes. br/RBPS/article/view/2994/2368>. Acesso em: 14 jan. 2014.

MEDEIROS, Cássia R. G. et al. A rotatividade de enfermeiros e médicos: um impasse na implementação da Estratégia de Saúde da Família. Ciência \& Saúde Coletiva, Rio de Janeiro, v. 15, supl. 1, p. 1.521-1.531, jun. 2010.

PAULA, Maria F. A formação universitária no Brasil: concepções e influências. Avaliação, Campinas, v. 14, n. 1, p.71-84, mar. 2009.

PEREIRA, Ingrid D. F.; LAGES, Itamar. Diretrizes curriculares para a formação de profissionais de saúde: competências ou práxis? Trabalho, Educação e Saúde, Rio de Janeiro, v. 11, n. 2, p. 319-338, maio/ago. 2013. Disponível em: <www.scielo.br/pdf/tes/v1ln2/ a04v1ln2.pdf>. Acesso em: 11 jan. 2014.

PINHEIRO, Virginia C. et al. Inserção dos egressos do curso de Odontologia no mercado de trabalho. Revista Gaúcha de Odontologia, Porto Alegre, v. 59, n. 2, p. 277-283, abr./jun. 2011.

RIBEIRO, Alessandra F. A competência profissional e a Estratégia Saúde da Família: discurso dos profissionais. Revista APS, Juiz de Fora, v. 11, n. 2, p. 136-144, 2008.

ROCHA, Ana A. R. M.; TRAD, Leny A. B. A trajetória profissional de cinco médicos do Programa Saúde da Família: os desafios de construção de uma nova prática. Interface: Comunicação, Saúde, Educação, Botucatu, v. 9, n. 17, p. 303-316, ago. 2005.

SANCHEZ, Heriberto F.; DRUMOND, Marisa M.; VILAÇA, Ênio L. Adequação de recursos humanos ao PSF: percepção de formandos de dois modelos de formação acadêmica em odontologia. Ciência \& Saúde Coletiva, Rio de Janeiro, v. 13, n. 2, p. 523-531, mar./abr. 2008.
SEGENREICH, Stella C. D.; CASTANHEIRA, Antonio M. Expansão, privatização e diferenciação da educação superior no Brasil pós-LDBEN/96: evidências e tendências. Ensaio: avaliação e políticas públicas em educação, Rio de Janeiro, v. 17, n. 62, p. 55-86, jan./mar. 2009.

SEVERINO, Antônio J. Expansão do ensino superior: contextos, desafios, possibilidades. Avaliação, Campinas, v. 14, n. 2, p. 253-266, jul. 2009.

SGUISSARDI, Valdemar. Modelo de expansão da educação superior no Brasil: predomínio privado/mercantil e desafios para a regulação e a formação universitária. $E d u$ cação \& Sociedade, Campinas, v. 29, n. 105, p. 991-1022, set./dez. 2008.

SILVA, Irani F. Dicotomia básico-profissional no ensino superior em saúde: dilemas e perspectivas. In: BATISTA, Nildo A.; BATISTA, Sylvia H. (Org.). Docência em saúde: temas e experiências. São Paulo: Editora Senac, 2004. p. $75-84$.

SOARES, Dulce H. P. A escolha profissional: do jovem ao adulto. São Paulo: Summus, 2002.

SONZOGNO, Maria C. Metodologias do ensino superior: algumas reflexões. In: BATISTA, Nildo A.; BATISTA, Sylvia H. (Org.). Docência em saúde: temas e experiências. São Paulo: SENAC, 2004. p. 75-84.

VALORE, Luciana A.; SELIG, Gabrielle A. Inserção profissional de recém-graduados em tempos de inseguranças e incertezas. Estudos e Pesquisas em Psicologia, Rio de Janeiro, ano 10, n. 2, p. 390-404. 2010. Disponível em: <www.revispsi.uerj.br/v10n2/ artigos/pdf/v10n2a07.pdf $>$. Acesso em: 6 jan. 2014.

VUigotsKiJ, Liev S. Análisis de las funciones psíquicas superiores. In: VUIGOTSKIJ, Liev S. Historia del desarrollo de las funciones psiquicas superiores. Havana, Cuba: Editorial Científico-Técnica, 1987. p. 104-128. (Texto original publicado em 1930). 
WESKA, Adriana R. et al. Comissão constituída pela portaria n. 126/2012 sobre a análise sobre a expansão das universidades federais, 2003 a 2012. Relatório. Brasília: 2012. Disponível em: <http://portal.mec. gov.br/index.php?option $=$ com_docman $\&$ task=doc_download\&gid=12386\&Itemid=>. Acesso em: 6 jan. 2014.

Recebido em 08/02/2012

Aprovado em 27/09/2013 